\title{
MACUNAÍMA, CARÁTER DA DESCONSTRUÇÃO OU DESCONSTRUÇÃO DO CARÁTER?
}

Eduardo Timbó

Mestrando em Literatura Brasileira pelo PPG de Letras Vernáculas / UFRJ

\begin{abstract}
RESUMO
O presente trabalho parte inicialmente da ideia suscitada por Jacques Derrida de que os limites entre literatura e filosofia não são facilmente identificados. A partir disso realizaremos uma aproximação entre Macunaíma, o herói sem nenhum caráter, livro de Mário de Andrade que se tornou expoente do Modernismo brasileiro, e a desconstrução derridiana, “abordagem filosófica” assim nomeada por Derrida.
\end{abstract}

\section{PALAVRAS-CHAVE}

Mário de Andrade, Modernismo, identidade, desconstrução

\section{ANTES, DURANTE E APÓS}

Macunaíma, o herói sem nenhum caráter, oitocentos exemplares custeados pelo próprio autor, saía do prelo em vinte e seis de Julho de 1928. Uma parcela da crítica classificara-o como rapsódia. Uma outra, preferiu tratá-lo, classificá-lo como um “coquetel” (Tristão de Ataíde). Em Morfologia do Macunaíma, Haroldo de Campos defende que "no coquetel, porém, havia método". ${ }^{1}$

Para Mário Raul de Andrade, tratava-se de uma "história”. A informação está presente no verso da página de rosto da primeira edição de Macunaíma. Ainda em 1927 publica um fragmento intitulado "O caso da cascata” na revista Verde, de Cataguases (MG), que viria a se tornar um dos capítulos de Macunaíma, ao qual se refere como "livro".

\footnotetext{
${ }^{1}$ CAMPOS. Morfologia do Macunaíma, p. 79.
} 
Chamá-lo de "livro Macunaíma” tratava-se muito provavelmente da mais honesta tentativa por parte do autor em referenciar a sua produção ficcional. Indecidido ainda em como nomeá-la, dotá-la de uma “feição” apaziguadora perante a crítica, público e quem sabe perante o próprio autor, e aqui entramos com o primeiro pé no motivo do presente trabalho, resolve batizá-lo de “' 'romance', no sentido culto do gênero, pois para ele, nessa época, a classificação correta seria 'romance no sentido folclórico do termo', conforme explicará publicamente em 1931”. 2

A questão, que passa longe de soar como desimportante parece finalmente elucidada por Mário a partir da ideia de "romance no sentido folclórico do termo", uma vez que Macunaíma caracteriza-se e mesmo notabiliza-se pelo uso farto e astuto do folclore brasileiro em consórcio com as ideias das vanguardas europeias.

No entanto, a solução apresenta-se como tangencial e impositiva, pois mesmo nutrindo-se do folclore brasileiro, como de fato acontece, ainda assim o termo "romance no sentido folclórico do termo” não o satisfaz na busca terminológica empreendida, nem antes, nem após a publicação, como bem sublinha Lopes na introdução à edição crítica de Macunaíma, ao dizer que “a indecisão pode ser vista logo em 1926, quando o autor se inclina sobre seu texto durante a primeira redação” e vai além:

Embora venha a declarar na crônica "Raimundo de Moraes", em 1931, que, desde a leitura do lendário recolhido por Koch-Grünberg, pensava em Macumaíma como um herói de um romance de literatura popular, e que considerava a si mesmo um rapsodo, não deixa de hesitar em eleger o termo definitivo de classificação. ${ }^{3}$

Não apenas antes e após, mas mesmo durante o processo de escrita de seu "livro", a justa nomeação, o termo que captaria a rede de especificidades ali imbricadas parece sempre lhe escapar. $\mathrm{O}$ aturdimento com a questão torna-se patente na tarefa de reescritura dos prefácios de Macunaíma, que procuram amortecer, ou antes, preparar o leitor para a saga. Quanto maior a procura, menores os resultados alcançados e esse paradoxo, um dos vários relacionados a sua obra, parece provocar irritação em seu autor.

No primeiro prefácio, a palavra "livro", de emprego constante, exime o escritor de uma precisão maior. Chega mesmo a existir um momento em que sua perplexidade, em face da própria ficção em desenvolvimento, o leva ( $\mathrm{sic}$ ) a escrever esta nota apensa: “(Este livro

\footnotetext{
${ }^{2}$ LOPES. Introdução, p. 16.

${ }^{3}$ LOPES. Introdução, p. 15. (grifos nossos)
} 
não passa duma antologia do folclore brasileiro)”, considerando até mesmo uma impossível acepção redutora, a qual, aliás, refutará com veemência no segundo prefácio. ${ }^{4}$

Refuta a si mesmo do primeiro para o segundo prefácio, não concordando com a sua própria “acepção redutora”. A questão que se coloca então seria o que tal indecisão reflete? De fato, procurando elucidar essa questão, Lopes aponta que o motivo gerador dessa grande incerteza seria “a consciência que Mário de Andrade manifesta de estar transgredindo os cânones da narrativa culta de seu tempo, realizando a experimentação na prosa”. 5

As diretrizes estéticas, os acordos ideológicos que caracterizam o nosso Modernismo, dentre os quais figura o "estado de espírito nacional,”6 não deixariam dúvida quanto a classificação que melhor caberia à Macunaíma, que seria a de “romance no sentido folclórico do termo”, nomeação que em nada desprivilegiaria a sua produção ficcional, nem lhe geraria dívida alguma perante o Modernismo.

Muito pelo contrário, tal classificação o resguardaria de pronto perante os seus iguais modernistas e garante uma solução apaziguadora quanto à crítica e público. Se bem observarmos, encontra-se presente na classificação adotada por Mário, mesmo que de forma hesitante, a equililibrada proporção entre o velho e novo, o folclore brasileiro e as vanguardas europeias encarnadas no Modernismo.

Não parece ser essa ainda a solução que vai por fim à questão do gênero ao qual Macunaíma se filia. O que podemos incorrer dessa querela classificatória é que Mário pressente já na empresa de classificar Macunaíma, que algo ali extrapolava, seja através da falta ou excesso, os limites do próprio Modernismo, ou que esses limites modernistas eram muito mais fluídos do que se imaginava.

Mário se divide em muitos no decorrer de sua produção, disseminando-se simultaneamente em vários campos, e essa informação nos parece relevante, como poeta, contista, ensaísta, um misto de etnólogo e antropólogo, e, por fim, como “rapsodo”. Sob essa ótica faz sentido os versos presentes em Remate dos Males, em que diz “Eu sou trezentos, sou trezentos-e-cinqüenta,/ Mas um dia afinal eu toparei comigo...". 7

\footnotetext{
${ }^{4}$ LOPES. Introdução, p. 16. (grifos nossos)

${ }^{5}$ LOPES. Introdução, p. 22.

${ }^{6}$ ANDRADE. Aspectos da literatura brasileira, p. 253.

${ }^{7}$ ANDRADE. De Paulicéia Desvairada a Café (poesias completas), p. 165.
} 
Em Macunaíma, e aqui entramos com os dois pés no motivo do presente trabalho, os trezentos, trezentos-e-cinquenta Mários que se disseminam pelas mais diversas áreas do conhecimento humano resolvem se encontrar, convergindo para a construção de um texto “desconstrutor” que reúne e aponta, ainda que de forma apenas intuitiva, para certas inquietações e questionamentos configuradores de uma cena pósmoderna.

O pressentimento de que seu "livro" de alguma forma estaria movendo os limites daquilo que conhecemos por Modernismo (veja-se aí também a ideia de moderno) poderá ser notado apenas tempos após a sua publicação através de declarações em cartas a outros escritores e amigos, e também através de ensaios e conferências. Sua motivação inicial pretendia ser "coerente com o projeto nacionalista em que estava empenhado no momento" e que envolvia uma grande parcela dos modernistas. ${ }^{8}$

No próprio Macunaíma, funde um Brasil múltiplo, mas ainda desconhecido por sua população, seja ela culta ou não, dando-lhe a feição de uma imensa massa que se põe em movimento através de uma dinâmica vertiginosa sobre a qual poderíamos projetar alguma identidade.

A “embrulhada geográfica proposital" tinha por objetivo criar uma espécie de geografia, fauna e flora lendárias que, libertando-se das contigências regionais, funcionasse como um elemento unificador da grande "pátria tão despatriada". ${ }^{9}$

Não há dúvidas quanto à coerência do projeto modernista que visava refletir a identidade, a cultura brasileira, e os projetos empreendidos, essencialmente por Mário, antes, durante e após a publicação de Macunaíma o testemunham muito bem. Mas era suspeito que Mário encarava esse projeto munido mais de perguntas do que de respostas. Nesse ponto ainda autor e obra são paradoxais, pois Mário sempre esteve engajado no projeto de pensar a cultura nacional, e para tanto, precisou coletá-la in loco, pois não havia dados sobre os quais se debruçar e esboçar um pensamento crítico, enfim pensar o povo brasileiro. Precisou coletá-la e refletí-la.

O paradoxo reside no fato de que, ao refletir sobre essa identidade, lançar-se em busca dos dados, não havia como prever o que então descobriria. E essa tarefa em que se pôs, acaba por revelar verdadeiras curiosidades, se assim quisermos chamar apenas.

\footnotetext{
${ }^{8}$ SOUZA. O tupi e o alaúde: uma interpretação de Macunaíma, p. 32.

${ }^{9}$ SOUZA. O tupi e o alaúde: uma interpretação de Macunaíma, p. 32. (grifos nossos)
} 
Na criação popular, o autor pudera encontrar, não sem surpresa, soluções bastante semelhantes a idéias suas sobre polifonia poética ou verso harmônico, quando observa, por exemplo, as enumerações com ausência de pausa nas emboladas. ${ }^{10}$

Suas ideias estavam em profunda ligação com as vanguardas europeias, e passa a estabeler ligações que, sob a ótica temporal, não seriam viáveis, mas que por algum influxo, um certo princípio de reversibilidade, adquirem validade. É o que nos diz Lopes ainda na introdução à edição crítica, afirmando que, "se quisermos ir mais longe, essa mesma rejeição das pausas ou das vírgulas, pudera ser também por ele encontrada no Manifesto técnico da literatura futurista, tão valorizado por nossos modernistas ". ${ }^{11}$ É o caso da passagem em que as danças religiosas da tribo de Macunaíma que "respeitava os velhos e freqüentava com aplicação a murua a pracê o torê o bacorocô a cucuicogue $(. . .)^{\prime}{ }^{12}$

De certa forma, a aproximação então pressentida por Mário abre um impasse ao refletir esse grande texto chamado cultura, por conseguinte, esse outro grande texto chamado cultura nacional. Então algumas "soluções” estéticas do Futurismo, a saber, a rejeição das pausas e vírgulas com intenção estética, já estavam presentes no folclore brasileiro, nas emboladas, coletadas por ele próprio?

Torna-se imprescindível, a partir daqui, a adoção de um aparato conceitual que já não se encontra pacificamente alojado sob a égide do Modernismo, mas, ao mesmo tempo deriva dele, se lembrarmos que “o moderno está inevitavelmente embutido no pós-moderno". 13

Entramos agora pelas sendas do que viríamos a chamar de pós-modernismo, encarado como "um fenômeno contraditório, que usa e abusa, instala e depois subverte, os próprios conceitos que desafia”. 14 A relação entre o moderno e o seu outro prevê um caráter de reversibilidade entre o projeto vanguardista do modernismo e a assunção da provisoriedade como atributo pós-modernista. Se o pós-moderno possui o moderno em si, de forma retroativa o moderno suscita o pós-moderno.

\footnotetext{
${ }^{10}$ LOPES. Introdução, p. 41.

${ }^{11}$ LOPES. Introdução, p. 42.

${ }^{12}$ ANDRADE. Macunaíma: o herói sem nenhum caráter, p. 7.

${ }^{13}$ HUTCHEON. Poética do pós-modernismo, p. 61.

${ }^{14}$ HUTCHEON. Poética do pós-modernismo, p. 61.
} 
As observações de Mário, além de sedutoras, são instauradoras de um acentuado desconforto, uma vez que a literatura modernista pretende juntar essas duas pontas, o popular e o erudito, em um só discurso, dando-lhe um caráter de discurso nacional. O discurso, entretanto, pode encontrar-se prenhe de referências que o localizem espacial, sociológica e historicamente, que o identifiquem no seu estatuto de nação, nutrindo-se de um “estado de espírito nacional”, pondo reparo a essa "pátria tão despatriada”, mas, por mais um paradoxo, esse não apenas marioandradino, mas pós-moderno, tal discurso “atua no sentido de demonstrar que todos os reparos são criações humanas, mas que, a partir desse mesmo fato, eles obtêm seu valor e também sua limitação. Todos os reparos são consoladores e ilusórios”. 15

Leda Hühne ecoa a pergunta marioandradina: "Por que negar a totalidade um passado artístico como inexpressivo ou romper com formas de expresssão, somente porque são velhas?” ${ }^{\text {"16 }}$ Mário reflete essa inquietação do nosso Modernismo, e ao mesmo tempo também pertencente a ele, no ensaio "O movimento modernista”:

Porque, embora lançando inúmeros processos e idéias novas, o movimento modernista foi essencialmente destruidor. Até destruidor de nós mesmos, porque o pragmatismo das pesquisas sempre enfraqueceu a liberdade da criação. ${ }^{17}$

A destruição é encarada por ele inicialmente como forma de superar um passado intelectual, delimitando suas bordas, provocando a diferença entre o velho imediato e o novo então aspirado pelo Modernismo. Mário critica a atitude do(s) presente(s), incluindo-se, e deposita no futuro a verdadeira amplitude não apenas da sua ação, mas do nosso Modernismo.

\section{ENTRE O (PÓS-) MODERNO}

Brasil amado não porque seja minha pátria,/Pátria é acaso de migrações e do pão nosso onde Deus der.

Mário de Andrade. Clã do jabuti.

\footnotetext{
${ }^{15}$ HUTCHEON. Poética do pós-modernismo, p. 24.

${ }^{16}$ HÜHNE. A estética aberta de Mário de Andrade, p. 75.

${ }^{17}$ ANDRADE. Aspectos da literatura brasileira, p. 263.
} 
A indecidibilidade em nomear seu livro, a dificuldade de traçar-lhe um conjunto de características que simplesmente o enquadre em determinado gênero textual, dá o tom sobre o qual Macunaíma se constrói, mesmo sendo consagrado pela crítica o termo “rapsódia” como termo definitivo, mas sempre com adendos. Mário não se decide, e quando o faz, ainda hesita, assim como Macunaíma, herói invertido que vê a busca por sua muiraquitã transformar-se em um "sem-número de fugas”" no campo vasto do céu”19.

O anti-herói marioandradino recebe o epíteto tanto de "herói de nossa gente" quanto de "herói sem nenhum caráter" durante a saga. O fato é que não deixa de soar irônico que um herói tão aplicadamente "anti” e "sem” no tocante ao seu caráter não seja também um herói “des”, e, portanto, descontínuo, desmembrado, descentralizado. ${ }^{20}$

As características citadas por Hutcheon encontram ressonância nas experimentações no campo artístico do pós-modernismo e nas teorizações provocativas de seus “filósofos” pós-estruturalistas, entre eles, Jacques Derrida, que aborda os vários aspectos da condição humana apenas através de textos, pois é consenso entre os pósmodernistas que "não podemos conhecer o passado, a não ser através de seus textos". ${ }^{21}$

Para tanto, trabalha em cima de uma “argumentação" reflexiva, que visa desestruturar verdades prontas, falsas dicotomias, a lógica ocidental (ou logocentrismo, como se refere à metafísica ocidental em alguns textos) presente na história do pensamento humano, chamando-a de desconstrução. Derrida não estrutura um procedimento de desconstrução, apenas incita-o descontruindo conceitos presentes em textos filosóficos e abordando textos literários.

Os movimentos de desconstrução não solicitam as estruturas do fora. Só são possíveis e eficazes, só ajustam seus golpes se habitam estas estruturas. Se as habitam de uma certa maneira, pois sempre se habita, e principalmente quando nem se suspeita isso. Operando necessariamente do interior, emprestando da estrutura antiga todos os recursos estratégicos e econômicos da subversão. ${ }^{22}$

Evita, dessa forma, caracterizar a desconstrução, dar-lhe uma feição apaziguadora que, no seu entender, seria a grande aporia, o erro fundamental da

\footnotetext{
${ }^{18}$ SOUZA. O tupi e o alaúde: uma interpretação de Macunaíma, p. 68.

${ }^{19}$ ANDRADE. Macunaíma: o herói sem nenhum caráter, p. 145.

${ }^{20}$ HUTCHEON. Poética do pós-modernismo, p. 34.

${ }^{21}$ HUTCHEON. Poética do pós-modernismo, p. 34.

${ }^{22}$ DERRIDA. Gramatologia, p. 30.
} 
filosofia do Ocidente. Ao contrário, apenas suscita o caráter da descontrução, desmascarando as supostas "verdades” que a razão, a linguagem, o texto ocidental carrega. Fato que o leva a afirmar que "a língua usual” não seria inocente ou neutra. Uma vez que "ela é a língua da metafísica ocidental e transporta não somente um número considerável de pressupostos de toda ordem, (...) [mas] pressupostos que estão enredados em um sistema”, 23

Macunaíma apresenta-se como um texto em desconstrução. De início, a tentativa gira em torno da construção da ideia de caráter (parodísticamente através da imagem do anti-herói, detidamente analisada por Souza em $O$ tupi e o alaúde), identidade como presença, e nacionalidade, mas termina desconstruindo as mesmas ideias durante o percurso da saga, gerando conflito com o "projeto estético e ideológico de um modernista com preocupações nacionalistas,"24 chegando mesmo Mário a falar com bastante amargor sobre essa inadequação de Macunaíma em carta a Álvaro Lins:

Mas a verdade é que eu fracassei. Se o livro todo é todo ele uma sátira, um não conformismo revoltado sobre o que é, o que sinto e vejo que é o brasileiro, o aspecto "gozado" prevaleceu. É certo que eu fracassei. Porque não me satisfaz botar a culpa nos brasileiros, a culpa tem que ser minha, porque quem escreveu o livro fui eu. ${ }^{25}$

Mais uma vez recorro a Derrida quando diz que "por ser inaugural, no sentido jovem deste termo, que a escritura é perigosa e angustiante”, no sentido de que nossas tentativas de amarrar o texto parecem resultar em trabalho inócuo, pois nem sempre nossas razões coincidem com as razões do texto que falam por si. ${ }^{26} \mathrm{O}$ autor não mais possui qualquer domínio sobre sua obra, e o paradoxo da escritura, da atividade literária, enfim, parece muito mais incerto e arriscado do que supunham mesmos os modernistas.

A transgressão, que é ponto marcante das vanguardas europeias e do nosso Modernismo, “implica que o limite esteja sempre em movimento,”27 mas a percepção aguçada desse evento e de suas manifestações será notada apenas com o advento do Pós-moderno. De forma que Mário não poderia notar claramente tais manifestações,

\footnotetext{
${ }^{23}$ DERRIDA. Posições, p. 25.

${ }^{24}$ LOPES. Introdução, p. 19.

${ }^{25}$ ANDRADE. Mário de Andrade escreve cartas a Alceu, Meyer e outros, p. 44.

${ }^{26}$ DERRIDA. A escritura e a diferença, p. 24-25.

${ }^{27}$ DERRIDA. Posições, p. 19.
} 
mesmo já habitando o seu texto, quando muito apenas se inquietar com elas, como de fato Macunaíma o faz.

\begin{abstract}
This article originally stems from the Jacques Derrida's idea that the boundaries between literature and philosophy are not easily identified. From this, we will carry out a rapprochement between Macunaima, o herói sem nenhum caráter, Mario de Andrade's book that became an exponent of Brazilian modernism, and Derrida's deconstruction, a “philosophical approach” so named by Derrida.
\end{abstract}

KEYWORDS

Mário de Andrade, Modernism, identity, deconstruction

\title{
REFERÊNCIAS
}

ANDRADE, Mário de. Macunaíma: o herói sem nenhum caráter. Edição crítica de Telê Porto Ancona Lopes. Rio de Janeiro: Livros Técnicos e Científicos; São Paulo: Secretaria da Cultura, Ciência e Tecnologia, 1978.

ANDRADE, Mário de. O movimento modernista. In: Aspectos da literatura brasileira. São Paulo: Editora Itatiaia, 2002.

ANDRADE, Mário de. De Paulicéia Desvairada a Café (poesias completas). São Paulo: Círculo do Livro, [s.d.].

ANDRADE, Mário de. Mário de Andrade escreve cartas a Alceu, Meyer e outros. Rio de Janeiro: Editora do Autor, 1968.

CAMPOS, Haroldo de. Morfologia do Macunaíma. São Paulo: Perspectiva, 1973.

DERRIDA, Jacques. Força e significação. In: A escritura e a diferença. Trad. Maria Beatriz Marques Nizza da Silva. São Paulo: Perspectiva, 2005.

DERRIDA, Jacques. Gramatologia. Trad. Miriam Chnaiderman e Renato Janine Ribeiro. São Paulo: Perspectiva, 2004.

DERRIDA, Jacques. Posições. Trad. Tomaz Tadeu da Silva. Belo Horizonte: Autêntica, 2001.

LOPES, Telê Porto Ancona. Introdução. In: ANDRADE, Mário de. Macunaíma: o herói sem nenhum caráter. Edição crítica organizada por Telê Ancona Lopes. Rio de Janeiro: Livros Técnicos e Científicos; São Paulo: Secretaria da Cultura, Ciência e Tecnologia, 1978. 
HÜHNE, Leda Miranda. A estética aberta de Mário de Andrade. Rio de Janeiro: Uapê, 2002.

HUTCHEON, Linda. Poética do pós-modernismo. Trad. Ricardo Cruz. Rio de Janeiro: Imago, 1991.

SOUZA, Gilda de Mello e. O tupi e o alaúde: uma interpretação de Macunaíma. São Paulo: Duas Cidades, 2003. (Coleção Espírito Crítico.) 